\title{
Domínio das planilhas eletrônicas por profissionais da área contábil-financeira na América hispânica*
}

Dominio de las hojas de cálculo por profesionales del área contable y financiera en Hispanoamérica Spreadsheets Knowledge of Professionals in Accounting and Financial Areas in Hispanic America

\section{Claudio de Souza Miranda ${ }^{\text {a }}$}

Universidade de São Paulo em Ribeirão Preto, Brasil

DOI: https://doi.org/10.11144/Javeriana.cc21-51.dpep

csmiranda@usp.br

ORCID: http://orcid.org/0000-0001-7511-1416

Recepção: 05/09/2018

João Paulo Resende de Lima

Aprovação: 10/10/2019

Universidade de São Paulo, Brasil

Publicação: 05/06/2020

ORCID: http://orcid.org/0000-0002-4703-2603

\author{
Elisabeth de Oliveira Vendramin \\ ESAN, Brasil \\ ORCID: http://orcid.org/0000-0002-9082-2256
}

\section{Resumo:}

Este estudo analisa a importância que os profissionais da área contábil e financeira atribuem às habilidades no uso de planilhas eletrônicas. Trata-se de um levantamento efetuado a partir de uma amostra de 237 profissionais (auditores, contadores, controllers e analistas financeiros) da América Hispânica, captados pelo LinkedIn. Observa-se que as planilhas eletrônicas estão entre as habilidades mais necessárias para estes profissionais e seu nível de conhecimento é, em média, elevado, principalmente entre os controllers. Por outro lado, ferramentas mais avançadas como Macros e Visual Basic for Application -VBA-, apresentam níveis de conhecimento ainda baixo. O conhecimento é adquirido principalmente no trabalho e no autoaprendizado mais que nas faculdades. Os resultados revelam que os novos entrantes têm um nível de conhecimento inferior aos seus pares. Igualmente, para a maioria dos profissionais as instituições de ensino superior deveriam capacitar melhor aos alunos nestas ferramentas.

Códigos JEL: M42, M49

Palavras-chave: educação contábil, competências profissionais, planilhas eletrônicas, tecnologia da informação.

\section{Resumen:}

Este estudio analiza la importancia que los profesionales del área contable y financiera atribuyen a las habilidades en el uso de hojas de cálculo. Se trata de un levantamiento efectuado a partir de una muestra de 237 profesionales (auditores, contadores, controllers y analistas financieros) de Hispanoamérica, captados por LinkedIn. Se observa que las hojas de cálculo están entre las habilidades más necesarias para estos profesionales y su nivel de conocimiento es, en promedio, elevado, principalmente entre los controllers. Por otro lado, herramientas más avanzadas como Macros y Visual Basic for Application -VBA- presentan un nivel de conocimiento inferior. El conocimiento es adquirido principalmente en el trabajo y por autoaprendizaje, más que en las universidades. Los resultados revelan que los nuevos trabajadores tienen un nivel de conocimiento inferior a sus pares. Igualmente, para la mayoría de los profesionales las instituciones de educación superior deberían capacitar mejor a los alumnos en el uso de estas herramientas.

Códigos JEL: M42, M49

Palabras clave: educación contable, competencias profesionales, hojas de cálculo, tecnología de la información.

\section{Abstract:}

This study analyses the perception of professionals about the skills using spreadsheets. It consists of a survey applied to a sample of 237 professionals (auditors, accountants, controllers and financial analysts) from Hispanic America, captured by LinkedIn. It is observed that using spreadsheets is considered one of the most necessary skills for these professionals, and their knowledge about it is, on average, high. That is especially the case for controllers. On the other hand, more advanced tools like Macros and Visual

\section{Autor notes}

a Autor para correspondência. Correio eletrônico: csmiranda@usp.brcsmiranda@usp.br 
Basic for Application (VBA) still show a low level of knowledge. Knowledge is acquired mainly at work and by self-learning. The results show that new entrants have a lower level of knowledge than their peers. Furthermore, for most professionals, undergraduate faculties must train better their students in using this kind of tool.

JEL Codes: M42, M49

Keywords: Accounting education, professional skills, spreadsheets, information technology.

\section{Introdução}

O aumento da competitividade nas empresas tem requerido, cada vez mais de profissional com amplas e diversas competências. Este fato tem aumentando a importância de estudos sobre as diversas competências profissionais necessárias ao desenvolvimento das atribuições de maneira eficaz e eficiente em todas as áreas de conhecimento. Especificamente acerca das competências do profissional contábil, a literatura apresenta, desde a década de 1990, diversos estudos que realizaram levantamentos das principais competências esperadas dos profissionais ligados à área contábil-financeira, independente de sua área de atuação. Tais pesquisas têm discutido esse fenômeno sob os mais diferentes olhares e percepções, abrangendo principalmente docentes e profissionais de mercado fora da academia.

Apesar de apresentar diferentes conceituações, variando de acordo com a área (Cardoso, Riccio e Albuquerque, 2009), no presente artigo entende-se a competência profissional como sendo a capacidade do indivíduo de articular e mobilizar conhecimentos, habilidades e atitudes (De Luiz, 2001).

No que tange às habilidades dos profissionais de contabilidade, as pesquisas prévias feitas com profissionais da área contábil-financeira, apresentam uma lista extensa que envolve aspectos de atividades profissionais e aspectos pessoais (Burnett, 2003; Chen et al., 2009; Bradbard, Alvis \& Morris, 2014). Além das pesquisas realizadas em diversos países, associações profissionais como a American Institute of Certified Public Accountants -AICPA - e American Accounting Association -AAA - também já publicaram relatórios indicando competências necessárias à profissão contábil, como exemplo cita-se o relatório emitido pela Pathways Commission (2015).

Dentre as competências encontradas nos trabalhos está o emprego de Tecnologias da Informação, com foco principalmente no uso de planilhas eletrônicas (Elsaadani, 2015; Willis, 2016). Sabe-se que as planilhas eletrônicas apresentam diversas funções que podem ser utilizadas para diferentes propósitos. Contudo, são poucos os trabalhos que aprofundam a discussão sobre suas funções e funcionalidades.

Bradbard et al. (2014) efetuaram um levantamento com 85 profissionais, ligados ao Institute of Management Accountants, sobre a importância do conhecimento relativos a trinta e dois tópicos de Excel, em diversos níveis de dificuldade. Ragland e Ramachandran (2014) realizaram um estudo semelhante, ao comparar, por meio de um questionário aplicado a contadores e estudantes de graduação, quais as funções usadas e/ou esperadas pelos estudantes, pós-graduandos, novos contratados e supervisores.

No contexto da América Latina, não foram encontradas pesquisas como as de Bradbard et al. (2014) e Ragland e Ramachandran (2014), demonstrando uma lacuna na literatura. Diante de tal cenário o objetivo deste trabalho é analisar, sob a ótica de profissionais de mercado ligados à área contábil-financeira, qual é o nível de conhecimento necessário sobre planilhas eletrônicas para o desenvolvimento de seu trabalho. Adicionalmente, se investigará quais deveriam ser os conhecimentos necessários aos recém-formados para o desenvolvimento de suas atividades profissionais. Visando responder a essa pergunta, o estudo tem como principal questão de pesquisa verificar o nível de proficiência desejado para os profissionais da área contábil financeira no uso de planilhas eletrônicas.

O presente trabalho justifica-se, com base no exposto por Bradbard et al. (2014), no fato de que as organizações, com frequência, enfatizam a importância de que novos profissionais contratados sejam proficientes em planilhas eletrônicas. Adicionalmente, Lee et al. (2018) destacam que não existe um consenso entre os empregadores de quais funções constituem a proficiência em planilhas eletrônicas, o que pode causar 
frustrações e maiores custos no processo de recrutamento e seleção de novos profissionais. Destaca-se ainda que a importância da proficiência em planilhas eletrônicas não é exclusiva às grandes empresas, ela é também presente nas médias e pequenas empresas, como mostra o trabalho de Bahador, Haider e Saat (2018).

Dessa forma, propiciar um melhor conhecimento sobre quais funções são mais usadas e consideradas mais importantes é um dos passos significativos para melhor preparar os profissionais que querem ingressar no setor contábil-financeiro. Além de contribuir para a prática, ao apresentar as funções mais importantes e mais utilizadas no mercado profissional, o estudo contribui para que as instituições de ensino possam alinhar suas disciplinas de tecnologia da informação com as expectativas do mercado. Além disso, o trabalho contribui para os profissionais de recrutamento e seleção ao aprofundar o nível de proficiência procurado pelo mercado. Igualmente, ele alimenta a literatura científica relacionada às discussões acerca das competências relacionadas à tecnologia da informação para os profissionais da área contábil-financeira.

$\mathrm{Na}$ seção seguinte é apresentado o referencial teórico que embasa este trabalho. Depois mostramse os aspectos metodológicos aplicados para sua execução. Por fim, são apresentados os resultados e as considerações finais, respectivamente.

\section{Referencial teórico}

\section{Competências e habilidades do profissional contábil}

O conceito de competência não é consensual na literatura, entretanto sua semântica já foi abordada por diversas linhas (Cardoso et al., 2009). Fleury e Fleury (2001) indicam que a compreensão desse conceito deve ser observada a partir de três dimensões: a primeira, relativa à pessoa, diz respeito à competência do indivíduo; já a segunda, é relativa às organizações (seu core competence); a terceira é a dos países, ou seja, seus sistemas educacionais e formação de competências.

$\mathrm{Na}$ dimensão relativa às pessoas, foco desta pesquisa, De Luiz (2001) aponta que a literatura corrente afirma, em termos gerais, que a competência profissional é a capacidade de articular e mobilizar conhecimentos, habilidades e atitudes, colocando-os em ação para resolver problemas e enfrentar as situações de imprevisibilidade em uma dada situação concreta de trabalho e em um determinado contexto cultural. Ampliando-se este conceito, Depresbiteris (1989), define a competência como um "conjunto identificável de conhecimentos (saberes), práticas/habilidades (saber fazer) e atitudes (saber ser) que mobilizados podem levar a um desempenho satisfatório".

$\mathrm{Na}$ literatura, muitos dos trabalhos listam as habilidades do uso de tecnologias da informação como importante e esta tem ganhado cada vez mais destaque. Isso decorre, de acordo com Elsaadani (2015), da alta velocidade das mudanças tecnológicas e sua adoção por parte das empresas. Assim, pode-se destacar que a Tecnologia da Informação -TI- está incluída entre os fatores que mais contribuem para promover o amplo crescimento econômico-financeiro, visto que automatiza tarefas e promove maior eficiência e eficácia nos processos.

Chen et al. (2009) apontam que a TI vem mudando o modo como as organizações operam. Devido a sua ampla utilização no mundo dos negócios, demanda novas habilidades e conhecimentos que os estudantes de contabilidade e finanças deverão dispor atualmente. Como as TI estão se tornando cada vez mais avançadas e demandadas pelo mercado, a educação contábil é desafiada por essas mudanças no ambiente em que os profissionais da área estão operando. Sendo assim, ensinar aos alunos de contabilidade apenas os tópicos de contabilidade tradicionais, pode colocá-los em desvantagem competitiva no mercado de trabalho.

Neste contexto, Burnett (2003) indica que a educação contábil está sempre pressionada a mudar seus métodos de ensino, a fim de sobreviver no ambiente econômico de negócios que sofre grandes mudanças com as novas tecnologias. Kearns (2014) aponta ainda que as investigações sobre a composição dos currículos 
do programa de Contabilidade têm sido intensas e destaca a importância do conhecimento dos sistemas de informações. No entanto ressalta que a aplicação de suas habilidades vem sendo assumida, porém não integrada na maioria dos programas de contabilidade.

Bradbard et al. (2014) mostram que as organizações com frequência enfatizam a importância de que novos profissionais contratados, sejam proficientes em Excel. Dessa forma, ao se ter um melhor conhecimento sobre quais funções são mais usadas, e consideradas mais importantes será possível preparar melhor os profissionais que querem ingressar no setor contábil-financeiro.

Acerca do profissional contábil a American Institute of Certified Public Accountants -AICPA- traz dois conjuntos de competências profissionais a serem desenvolvidas: as competências gerais (core competencies) e as competências integradas para o ensino contábil (Integrated Competency-Based Framework for Accounting Education). Em ambos os conjuntos de competências a importância da tecnologia e das planilhas eletrônicas é destacada. As core competencies são apresentadas e descritas na tabela 1.

TABELA 1

Competências do profissional contábil-financeiro segundo a AICPA

\begin{tabular}{|c|c|c|}
\hline Dimensăo & Competência & Descriçăo \\
\hline \multirow{3}{*}{$\begin{array}{l}\text { Competências } \\
\text { Funcionais }\end{array}$} & Divulgação & $\begin{array}{l}\text { Desenvolver habilidades de divulgação e } \\
\text { apresentaçăo ao preparar e formatar dados para } \\
\text { análises e apresentaç̄̄es. }\end{array}$ \\
\hline & Pesquisa & $\begin{array}{l}\text { Desenvolver habilidades de pesquisa ao } \\
\text { comparar as demonstraç̋́es contábeis de duas } \\
\text { companhias do mesmo ramo de atuaçăa. }\end{array}$ \\
\hline & $\begin{array}{l}\text { Aproveitamento da } \\
\text { tecnologia }\end{array}$ & $\begin{array}{l}\text { Aproveita a tecnologia, por meio do Excel, para } \\
\text { análise de dados e construção de gráficos. }\end{array}$ \\
\hline \multirow{5}{*}{$\begin{array}{l}\text { Competências } \\
\text { Pessoais }\end{array}$} & $\begin{array}{l}\text { Solução de } \\
\text { problemas e Tomada } \\
\text { de decisões }\end{array}$ & $\begin{array}{l}\text { Desenvolver a capacidade de solucionar } \\
\text { problemas ao interpretar e comparar informaç̋̃es } \\
\text { financeiras de duas indústrias do mesmo setor de } \\
\text { atuação. Desenvolver a capacidade de tomada de } \\
\text { decisões ao emitir uma opiniâo sobre a situaçẵo } \\
\text { de uma empresa. }\end{array}$ \\
\hline & Interaç̄̃es & $\begin{array}{l}\text { Desenvolver habilidades interacionais ao trabalhar } \\
\text { em grupo para elaborar relatórios e para avaliar } \\
\text { os trabalhos dos colegas ao utilizar a avaliaçăo } \\
\text { por pares. }\end{array}$ \\
\hline & Liderança & $\begin{array}{l}\text { Desenvolver habilidades de liderança ao trabalhar } \\
\text { em grupo. }\end{array}$ \\
\hline & Comunicação & $\begin{array}{l}\text { Desenvolver habilidades de comunicação ao } \\
\text { trabalhar em grupos e preparar relatórios escritos. }\end{array}$ \\
\hline & Gerenciar projetos & $\begin{array}{l}\text { Desenvolver a capacidade de gerenciar projetos } \\
\text { ao trabalhar com outros colegas, definir metas e } \\
\text { prazos. }\end{array}$ \\
\hline $\begin{array}{l}\text { Competências } \\
\text { Gerenciais }\end{array}$ & $\begin{array}{l}\text { Pensamento } \\
\text { crítico/estratégico }\end{array}$ & $\begin{array}{l}\text { Desenvolver habilidades de pensamento crítico e } \\
\text { estratégico ao sintetizar pesquisas e realizar } \\
\text { análises para emitir uma opiniẫo acerca da } \\
\text { situaçăa de uma empresa. }\end{array}$ \\
\hline
\end{tabular}

Fonte: adaptado de Grimm e Blazovich (2016).

\section{Competências tecnológicas esperadas na área contábil-financeira}

Uma vez que a tecnologia é um componente importante na estratégia competitiva das empresas e continua a se desenvolver continuamente, é esperado que os funcionários dessas empresas dominem cada vez mais habilidades tecnológicas. No caso específico da contabilidade, não só as empresas, mas também as associações de classe e os órgãos reguladores - AAA e AICPA - têm emitido pareceres e opiniões técnicas acerca da relação entre a contabilidade, a tecnologia e o ensino da tecnologia nos cursos de contabilidade (Willis, 2016).

A Pathways Commission (2015), na recomendação número 4, afirma que é preciso olhar para a educação contábil e refletir sobre os desafios e oportunidades que a tecnologia proporciona, tanto para o desenho dos currículos dos cursos e as estratégias de aprendizagem efetiva, quanto para a própria prática contábil. Outro ponto destacado nesse relatório refere-se à integração dos aspectos pedagógicos, tecnológicos com os conhecimentos específicos da contabilidade, que devem ser trabalhados de maneira integrada e se sobrepor em diversos momentos, conforme mostrado no esquema apresentado na figura 1. 


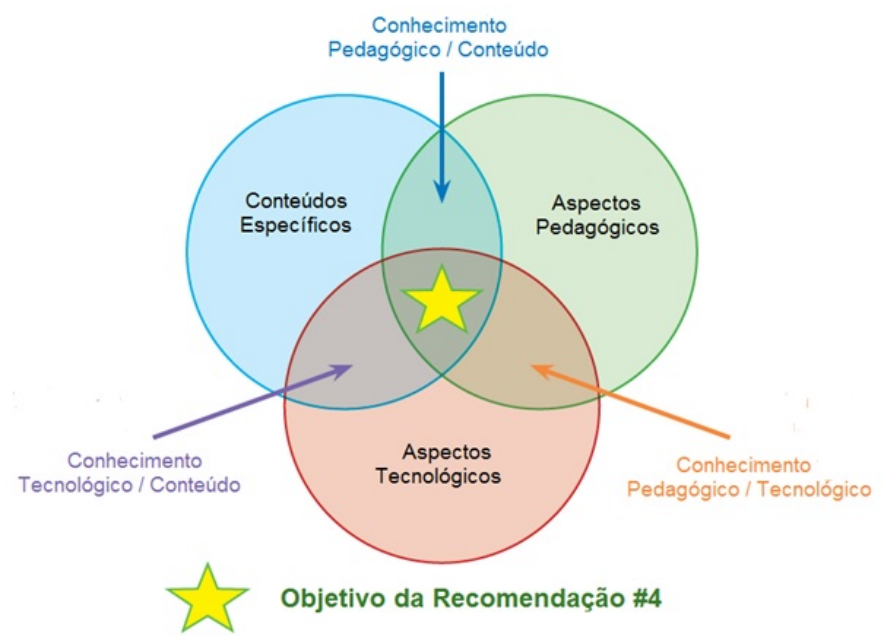

FIGURA 1

Modelo de conteúdo e conhecimento pedagógico sobre tecnologia

Fonte: Adaptado de Pathways Commission (2015).

Uma das principais ferramentas tecnológicas utilizadas pelos profissionais das áreas contábeis e financeiras são as planilhas eletrônicas. De acordo com Willis (2016) o uso das planilhas eletrônicas em contextos contábeis teve início em 1974 com o VisiCalc. Desde então, as planilhas eletrônicas tem evoluído e se tornado indispensáveis para o bom trabalho de um profissional da área contábil-financeira. A importância das planilhas eletrônicas no contexto do profissional de contabilidade já foi analisada e atestada por diversos trabalhos, conforme apresentado na tabela 2.

TABELA 2

Estudos anteriores a respeito das competências tecnológicas do profissional contábil-financeiro

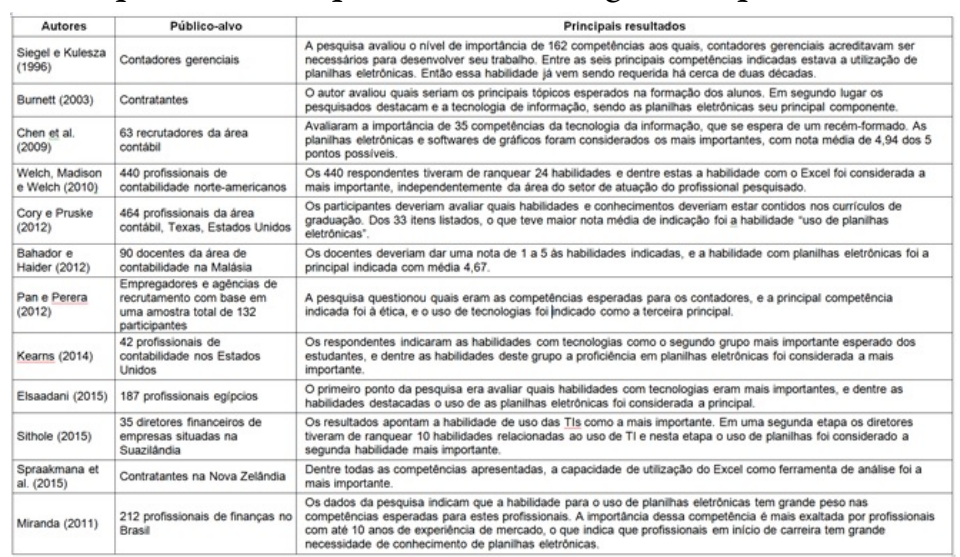

Fonte: elaboração própria com base no levantamento de literatura.

Apesar dos trabalhos apresentados na tabela 2, cabe ressaltar que a grande importância dada às competências tecnológicas, nem sempre é consenso. O trabalho de Osmani, Hindi e Al-Esmail (2017), feito com estudantes de uma universidade norte-americana, mostra que as habilidades tecnológicas são vistas apenas como a $11^{\text {a }}$ mais importante de uma lista de 15 habilidades propostas.

As pesquisas listadas indicam a importância do conhecimento de planilhas eletrônicas pelos profissionais, mas não apresentam quais conteúdos de planilhas eletrônicas seriam importantes de serem estudados. Bradbard et al. (2014) apontam que um melhor conhecimento sobre quais funções são mais usadas e consideradas mais importantes é um dos passos significativos para melhor preparar os profissionais que querem ingressar no setor contábil-financeiro. 
Com esse objetivo, Bradbard et al. (2014) efetuaram um levantamento junto a 85 profissionais sobre a importância do conhecimento referente a trinta e dois tópicos de Excel, com diferentes níveis de dificuldade. A pesquisa buscou avaliar a importância do que se deveria ter de domínio no uso do Excel, a partir da expectativa dos conhecimentos esperados pelos recém-formados e das práticas do uso do Excel do entrevistado.

O estudo de Ragland e Ramachandran (2014), feito nos Estados Unidos com 195 contadores e profissionais de finanças e 52 estudantes de graduação da Southeastern University, compara quais são as funções usadas e/ou esperadas pelos estudantes, pós-graduandos, novos contratos e supervisores.

A pesquisa identifica, entre os grupos entrevistados, quais as funções do Excel que são percebidas como importantes e as que são realmente usadas. Os resultados indicam que as respostas dos novos contratados e dos supervisores foram bem semelhantes, sendo as principais funções para o primeiro grupo: as funções básicas, as de formato, filtrar e classificar dados, os atalhos de teclado e pesquisa vertical e/ou horizontal. Para o grupo de supervisores inverte-se o segundo com o terceiro tópico, mostrando, assim, que as funções que os novos contratados percebem como sendo mais importantes são também as que os supervisores percebem e sabem que são as mais usadas.

Entre as principais contribuições do estudo de Ragland e Ramachandran (2014), destaca-se que conhecer as funções percebidas como sendo importantes e as mais utilizadas pode permitir que professores de contabilidade e finanças possam adaptar os currículos dos seus cursos para atender às demandas de mercado. Isto pode deixar os alunos mais preparados para possíveis carreiras na área contábil, visto que as organizações anseiam por profissionais que tenham desenvolvido não só habilidades de pensamento analítico e crítico, mas também o uso de ferramentas como o Excel.

\section{Metodologia}

O delineamento deste estudo está baseado na tipologia proposta por Beuren (2006). Esta pode caracterizase, no tocante aos objetivos, como descritiva, pois buscará demonstrar o comportamento da população investigada. Quanto aos procedimentos, trata-se de um levantamento de tipo quantitativo, fazendo uso de instrumentos estatísticos para análise dos dados.

O levantamento consiste em um Survey implementado com o objetivo de responder questões acerca da distribuição de uma variável ou das relações entre características de pessoas ou grupos, da maneira como ocorrem em situações naturais (Martins e Theóphilo, 2009).

Especificamente, este levantamento foi uma $W$ ebsurvey. Trata-se de um levantamento efetuado via internet (Umbach, 2004), cujas especificidades, de modo geral, utilizam os mesmos princípios metodológicos das surveys (Callegaro et al., 2015). Cabe ressaltar que o desenvolvimento de websurveys tem alguns pontos negativos. De acordo com Dillman (2000), um desses pontos é a possibilidade de o respondente não ter acesso eletrônico, ou mesmo de se conseguir os endereços eletrônicos da população almejada. Para mitigar este risco, os contatos dos profissionais que participaram da pesquisa foram captados através do LinkedIn que é uma rede social profissional. A captação de contatos de profissionais de uma determinada área através do LinkedIn, para pesquisas acadêmicas, já pode ser observada na literatura, como nos estudos de Costa (2012), Miranda (2011) e Waaijer et al. (2015).

Os profissionais públicos-alvo desta pesquisa foram os que tinham, principalmente, a denominação de Controller (gerente de controladoria), CFO (Chief Finance Officer), Diretor financeiro, Gerente financeiro, Gerentes/Analistas de custos, Contador, Auditores Externos e Internos, de todos os países continentais de língua espanhola da América Latina. A base levantada consistiu numa amostra de 1051 profissionais, que se prontificaram em responder à pesquisa. 
O instrumento de coleta de dados foi desenvolvido tomando como base principal os trabalhos de Bradbard et al. (2014) e Ragland e Ramachandran (2014), instrumentos já validados, mas que tinham diferentes formas de avaliação e de conteúdo. Visando melhor refletir a realidade estudada, foram inseridos aspectos de importância das planilhas na atividade profissional e da importância desta habilidade, bem como a inserção e retirada de algumas ferramentas listadas nos trabalhos prévios ao instrumento de coleta.

Antes da aplicação dos questionários, foram efetuados pré-testes para avaliar possíveis problemas em sua concepção. O questionário foi aplicado através do software Lime Survey. e foram feitas três ondas de solicitação de preenchimento em julho de 2017.

\section{Resultados e discussões}

\section{Caracterização da amostra}

A amostra total do estudo compreende 23,5\% dos profissionais selecionados, resultando em 247 respondentes, dos quais $72,1 \%$ eram do sexo masculino e $27,9 \%$ do sexo feminino. Em termos de idade, observa-se pela tabela 3 que $87,4 \%$ concentram-se entre 26 e 50 anos. No que tange à formação, $77,3 \%$ tinham graduação em contabilidade/auditoria, 11,7\% em Administração, 2,4\% em Economia, 2,4\% em Engenharia Comercial e $6,1 \%$ em outros cursos.

TABELA 3

Faixa etária

\begin{tabular}{|c|c|}
\hline Idade & $\begin{array}{c}\text { Percentual } \\
(\%)\end{array}$ \\
\hline Até 25 anos & 2,4 \\
\hline 26 a 30 anos & 23,1 \\
\hline 31 a 35 anos & 21,1 \\
\hline 36 a 40 anos & 17,8 \\
\hline 41 a 50 anos & 25,5 \\
\hline 51 a 60 anos & 9,3 \\
\hline Mais de 60 anos & 0,8 \\
\hline
\end{tabular}

Fonte: dados da pesquisa.

A tabela 4 demonstra uma distribuição uniforme do tempo de formação dos profissionais. O tempo após a conclusão do curso é bem equilibrado, sendo a menor taxa (19,8\%) a conclusão entre 11 a 15 anos.

TABELA 4

Tempo de conclusão do curso

\begin{tabular}{|c|c|}
\hline Tempo & $\begin{array}{c}\text { Percentual } \\
\%\end{array}$ \\
\hline Até 5 anos & 21,9 \\
\hline De 6 a 10 anos & 24,7 \\
\hline De 11 a 15 anos & 19,8 \\
\hline Mais de 15 anos & 33,6 \\
\hline
\end{tabular}

Fonte: dados da pesquisa.

Quando questionados a respeito da continuidade dos estudos depois da graduação, observa-se que $71,3 \%$ fizeram cursos de especialização/MBA, principalmente nas áreas de Contabilidade e Auditoria (25,5\%), Controladoria e Finanças (22,7\%), Administração e afins (17,0\%). Observa-se ainda que 49,8\% 
fizeram mestrado, principalmente em Contabilidade (14,6\%) e Administração (27,1\%), e apenas 3,6\% têm doutorado.

Em termos de localização, obteve-se respondentes de todos países de língua espanhola da América do Sul e Central (continental), conforme demonstra a tabela 5. Os países de maior PIB da região (Argentina, Chile, Colômbia, México, Peru) representam 58,7\% dos respondentes.

TABELA 5

Pais de origem

\begin{tabular}{|c|c|}
\hline País & Percentual (\%) \\
\hline Chile & 13,4 \\
\hline Colômbia & 13,0 \\
\hline México & 12,1 \\
\hline Argentina & 10,9 \\
\hline Peru & 9,3 \\
\hline Venezuela & 5,7 \\
\hline Paraguai & 5,3 \\
\hline Guatemala & 4,9 \\
\hline Nicarágua & 4,5 \\
\hline Uruguai & 4,5 \\
\hline Costa Rica & 3,6 \\
\hline Panamá & 3,2 \\
\hline Honduras & 2,8 \\
\hline Bolivia & 2,4 \\
\hline El Salvador & 2,4 \\
\hline Equador & 2,0 \\
\hline
\end{tabular}

Fonte: dados da pesquisa.

Conforme exposto anteriormente, na busca dos respondentes procurou-se captar profissionais que atuassem em diversas funções da área contábil-financeira, e solicitou-se que eles indicassem a área da organização que melhor definisse sua atuação. Observa-se pela tabela 6 uma maior concentração na área de auditoria, seguido da área financeira, contábil e controladoria.

TABELA 6

Área de atuação

\begin{tabular}{|c|c|}
\hline Área de atuação & Percentual (\%) \\
\hline Auditoria & 51,4 \\
\hline Financeira & 22,3 \\
\hline Contábil & 15,4 \\
\hline Controladoria & 10,9 \\
\hline
\end{tabular}

Fonte: dados da pesquisa.

Entre os que indicaram ser auditor, $49,6 \%$ atuam como auditores externos, $45,7 \%$ como auditores internos e 4,7\% em outras áreas de auditoria. Entre os que indicaram ser da área financeira ou de controladoria, tinham como principais atividades o desenvolvimento do orçamento (72,3\%), contabilidade de custos (67,5\%), elaboração das demonstrações contábeis $(67,5 \%)$ e análise financeira de risco $(66,3 \%)$. E entre os que 
indicaram ser da área contábil, 76,9\% indicaram como principal atividade a contabilidade de custos (76,9\%), contabilidade financeira $(74,4 \%)$ e Fiscal/Tributária (66,7\%).

Em termos de experiência profissional, na área de atuação indicada, a tabela 7 demonstra que 50,6\% tem até 10 anos de experiência.

TABELA 7

Experiência profissional (em anos)

\begin{tabular}{|c|c|}
\hline Experiência profissional & Percentual (\%) \\
\hline Até 5 anos & 20,6 \\
\hline De 6 a 10 anos & 30,0 \\
\hline De 11 a 15 anos & 15,8 \\
\hline De 16 a 20 anos & 14,6 \\
\hline Mais de 20 anos & 19,0 \\
\hline
\end{tabular}

Fonte: dados da pesquisa.

Dado que em termos do cargo indicado haveria grandes divergências de nomenclatura, utilizou-se como forma de avalição da posição hierárquica os dados da tabela 8 , que indicam o distanciamento hierárquico do pesquisado em relação ao principal gestor da área indicada de atuação. De maneira geral a maior parte (63,5\%) está no primeiro nível hierárquico ou o imediatamente abaixo. Mas a distribuição não é coesa entre todas as áreas de atuação (Qui-quadrado - 0,002).

Em relação à caracterização das empresas, buscou-se três variáveis de controle, sendo a primeira a origem do capital. Encontrou-se que 64\% são de capital nacional, 30,8\% de capital internacional e 5,3\% são joint ventures de capital misto nacional e internacional.

TABELA 8

A partir da sua posição no organograma da área de atuação que indicou, ¿quantos níveis hierárquicos lhe separam do principal executivo desta área?

\begin{tabular}{|l|c|c|c|c|c|}
\hline & $\begin{array}{c}\text { Auditoria } \\
(\%)\end{array}$ & $\begin{array}{c}\text { Contábil } \\
(\%)\end{array}$ & $\begin{array}{c}\text { Financeira } \\
(\%)\end{array}$ & $\begin{array}{c}\text { Controladoria } \\
(\%)\end{array}$ & $\begin{array}{c}\text { Total } \\
(\%)\end{array}$ \\
\hline $\begin{array}{l}\text { 0, ou então mesmo } \\
\text { nivel }\end{array}$ & 11,8 & 10,5 & 27,3 & 37,0 & 17,8 \\
\hline $\begin{array}{l}\text { 1, ele é seu superior } \\
\text { imediato }\end{array}$ & 42,5 & 52,6 & 52,7 & 37,0 & 45,7 \\
\hline $\begin{array}{l}\text { 2 niveis de separação } \\
\text { do principal executivo }\end{array}$ & 29,9 & 34,2 & 12,7 & 18,5 & 25,5 \\
\hline $\begin{array}{l}\text { 3 ou mais niveis de } \\
\text { separação do principal } \\
\text { executivo }\end{array}$ & 15,7 & 2,6 & 7,3 & 7,4 & 10,9 \\
\hline
\end{tabular}

Fonte: dados da pesquisa.

Em termos de área de atuação, a maior parcela indicou serem empresas de serviços (48,6\%), indústria (25,5\%), comércio (19\%), setor público (4\%), agronegócio (2,0\%) e terceiro setor (0,8\%). Para avaliar o tamanho do negócio, solicitou-se o número de funcionários, apresentados na tabela 9.

TABELA 9

Número de funcionários

\begin{tabular}{|c|c|}
\hline Número de Funcionários & Percentual (\%) \\
\hline Até 100 & 31,2 \\
\hline De 101 a 500 & 27,9 \\
\hline De 501 a 1000 & 13,0 \\
\hline De 1000 a 2500 & 12,1 \\
\hline Mais de 2500 & 15,8 \\
\hline
\end{tabular}

Fonte: dados da pesquisa. 


\section{Conhecimento em ferramentas de planilhas eletrônicas}

Apresenta-se a seguir os dados das respostas específicas sobre o uso da ferramenta de planilhas eletrônicas. Além da estatística descritiva, serão efetuados os testes não paramétricos de Mann Whitney, Kruskall Wallis e Qui-quadrado para avaliar a existência de avaliação entre grupos de controle. Os grupos de controle definidos foram: área de atuação, posição hierárquica, sexo, setor de atuação da empresa, curso de graduação, idade, pais de origem (separados entre os de maior PIB e os demais), experiência profissional e tamanho da empresa que atua.

O primeiro questionamento efetuado foi uma avaliação geral do nível de conhecimento a partir de uma escala de dez pontos, sendo "1" baixíssimo conhecimento e "10" como amplo conhecimento, incluindo Macros e programação VBA. A nota média encontrada foi 7,2, mediana 7 e moda 8 . O desvio padrão foi de 1,5 , assim, indicando uma concentração das notas. De maneira geral $12,6 \%$ dos entrevistados indicaram nota de 1 a $5,72,1 \%$ de 6 a 8 e $15,4 \%$ de 9 a 10.

A partir do teste de Kruskal-Walis observa-se diferença significativa de média apenas ao se analisar a experiência profissional. De maneira geral, quanto maior a experiência, maior foi a nota atribuída, indo de 6,8 para os profissionais com experiência de até cinco anos, até 7,8 para aqueles com mais de vinte anos de experiência.

Apesar de não ser observada diferença significativa em termos de área de atuação, os profissionais que atuam na área de Controladoria tiveram a maior média $(7,9)$ seguidos de Finanças $(7,4)$, Auditoria $(7,1)$ e Contabilidade $(6,7)$.

Além da própria avaliação do conhecimento, questionou-se sobre o nível de capacitação no uso de planilhas eletrônicas das novas contratações na organização, também com uma nota de 1 a 10 . A média observada foi de 6,8 com desvio padrão de 1,9 , apresentando a mesma concentração de notas da questão anterior. A nota entre 1 e 5 representou 22,7\% das notas, entre 6 e 8 representou 57,9\% e entre 9 e 10 totalizou 19,4\%. Não são observadas diferenças significativas de avaliação entre os grupos de controle.

Procurando avaliar a origem do nível de conhecimento indicado, questionou-se o percentual de origem do conhecimento a partir de quatro possíveis fontes: Faculdade, Trabalho, Cursos e treinamentos, autoaprendizagem. A tabela 10 indica que a principal origem de aprendizado de planilhas é no local de trabalho, seguido da autoaprendizagem, mas ambos também têm o maior desvio. A menor faixa de aprendizagem indicada ocorre em cursos e treinamentos.

TABELA 10

Origem do conhecimento de planilhas eletrônicas

\begin{tabular}{|c|c|c|}
\hline Origem & Média (\%) & Desvio padrão (\%) \\
\hline Trabalho & 51,5 & 22,3 \\
\hline Auto aprendizado & 22,6 & 19,5 \\
\hline Faculdade & 14,8 & 14,5 \\
\hline Curso e treinamentos & 11,1 & 12,3 \\
\hline
\end{tabular}

Fonte: dados da pesquisa.

Observa-se, pelo teste de Kruskal-Walis, diferenças significativas de aprendizagem na faculdade nas variáveis idade e posição hierárquica. Em relação à idade, os mais velhos com 50 anos ou mais indicavam um percentual menor dos que os mais novos (6,5\% para 51 a 60 anos e $10 \%$ para maiores de 60 anos). Em relação à posição hierárquica, os que estavam no topo da hierarquia foram os que indicaram menor percentual para a faculdade como fonte de aprendizagem $(9,6 \%)$, o que pode ser reflexo da variável anterior de idade, visto que os profissionais de maior nível hierárquico são mais velhos. Desta forma os cursos de graduação possivelmente não ofereciam disciplinas voltadas para a área de TI na época de sua graduação. Essa diferença pode ser avaliada como reflexo da evolução tecnológica e da consequente utilização nas Instituições de Ensino. 
Esse dado demonstra a distância entre academia e mercado mostrada em trabalhos como o de Marin, Lima e Casa Nova (2014).

Apesar de a faculdade ter sido indicada como uma das menores fontes de aprendizagem, ao se questionar sobre a importância do aprendizado delas nas instituições de ensino, a partir de uma escala de importância de "1" a "10", a média encontrada foi de 8,1 com desvio padrão de 1,8. Em nenhum dos grupos de controle foi observada diferença significativa.

Tentando compreender a importância das planilhas eletrônicas no trabalho dos profissionais, foram feitos dois questionamentos. No primeiro, listaram-se as dez habilidades dos profissionais da área financeira expostas anteriormente na revisão de literatura, e solicitou-se a indicação de qual seria o ranking de importância da habilidade com planilhas eletrônicas. O valor atribuído a cada habilidade era de " 1 " a "10", sendo 1 como a habilidade de menor importância, e 10 como a de maior importância.

Observa-se que $27,9 \%$ dos respondentes indicaram essa habilidade como sendo entre a $\sigma^{\mathrm{a}}$ e $10^{\mathrm{a}}$ importante. Para o 51,4\% dos respondentes, por sua parte, essa habilidade foi localizada entre a $3^{\text {a }}$ e $5^{\text {a }}$. Já para um 20,6\%, ela atinge a $1^{\mathrm{a}}$ e $2^{\mathrm{a}}$ posição. A moda e a mediana de posição no ranking foram de $4^{\mathrm{a}}$ posição. A importância da habilidade com planilhas eletrônicas, demonstrada nesta pesquisa, repetem os achados internacionais de Cory e Pruske (2012) e Bahador e Haider (2012).

Foram observadas diferenças significativas nos grupos de controle: posição hierárquica e setor de atuação. No que se refere à posição hierárquica, os profissionais que ocupam o nível mais alto indicam esta habilidade apenas como a $6^{a}$ mais importante, enquanto os demais estão na faixa média encontrada. Já na variável "setor de atuação da empresa”, observa-se diferenças apenas entre os profissionais da indústria que colocam esta habilidade na quinta posição.

Questionou-se ainda a importância das planilhas para a execução das atividades de sua área de atuação. A escala utilizada foi igual à do questionamento anterior - 1 a 10 , sendo 1 a menos importante e 10 a mais importante. A nota média encontrada foi 8,2, sendo que as notas entre 1 e 5 representaram apenas 6,5\%; entre 6 e 8 representou $42,9 \%$ e entre 9 e 10 foi de 50,6\%. Esta percepção de importância é comum em quase todos os grupos avaliados, exceto pela análise de hierarquia em que a importância tem uma relação inversamente proporcional com o nível hierárquico. Entre os de maior posição hierárquica a média de importância é 7,6, subindo conforme o nível hierárquico desce, chegando a 9,1 entre os que estão no $3^{\circ}$ nível ou mais.

No mercado existem algumas ferramentas de planilha eletrônica ativas e outras descontinuadas. Questionados sobre quais planilhas eletrônicas os profissionais tinham experiência, $100 \%$ indicaram ter conhecimento no Excel, 12,1\% no Calc da OpenOffice, e 16,2\% no descontinuado Lotus 1-2-3.

Com base inicial nos trabalhos de Ragland e Ramachandran (2014) e Bradbard et al. (2014), criouse uma lista de 27 funções, ferramentas e atividades que podem ser desenvolvidas a partir de planilhas eletrônicas. Sobre estas, solicitou-se que os profissionais indicassem seu nível de conhecimento sobre as mesmas, indicando se teriam: i) nenhum conhecimento; ii) conhecimento mas sem experiência de uso; iii) alguma experiência; ou iv) bastante experiência. A tabela 11 apresenta o nível de conhecimento indicado pelos profissionais, sendo que a ordem é apresentada em função do nível de indicação de bastante experiência. 
TABELA 11

Nível de conhecimento de funções, ferramentas e atividade

\begin{tabular}{|c|c|c|c|c|c|c|}
\hline Funçäo, ferramenta, atividade & $\begin{array}{l}\text { Nenhum } \\
\text { conhecimento } \\
(\%) \text { (\%) }\end{array}$ & $\begin{array}{l}\text { Conhecimeto } \\
\text { sem uso } \\
(\% \%)\end{array}$ & $\begin{array}{c}\text { Alguma } \\
\text { experiécia } \\
(\%)\end{array}$ & $\begin{array}{l}\text { Bastante } \\
\text { experiente } \\
(\%)\end{array}$ & 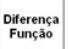 & $\begin{array}{c}\text { Diferenca } \\
\text { Hierarquia }\end{array}$ \\
\hline Funģes Basicas (ex Somare subtrair) & 0,00 & 0,81 & 5.26 & 93,93 & & \\
\hline Funģbes de filtrar, classificar dadose e subtotalizar. & 0,00 & 0,81 & 11,34 & 87,85 & & \\
\hline Funģ̧es de formataç̧o & 0.00 & 1,21 & 11,74 & 87,04 & & \\
\hline Usar funnsbes de procura (PROCV e PROCH) & 0.81 & 2,83 & 23,89 & 72,47 & & \\
\hline $\begin{array}{l}\text { Usar collula absoluta e relativiva de enderescamentito } \\
\text { (fxixaşo) }\end{array}$ & 1,62 & 3.24 & 23.08 & 72,06 & & \\
\hline $\begin{array}{l}\text { Usar a s condiğes em tormulas com O SE, CONT. SE } \\
\text { S SOMASE. }\end{array}$ & 0.00 & 3.64 & 28,74 & 67,61 & - & \\
\hline Tabelas Dinamicas & 2,43 & 7.69 & 34.82 & 55,06 & & \\
\hline 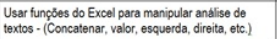 & 2.02 & 15.38 & 28,34 & 54.25 & & \\
\hline Usar formataşbo condicional & 5.67 & 14.98 & 29,15 & 50.20 & & \\
\hline $\begin{array}{l}\text { Usar diversos tipos de funçáo para ciar formulas } \\
\text { complexas (ex: se com PROCV }\end{array}$ & 4.45 & 14,17 & 31,98 & 49,39 & . & \\
\hline 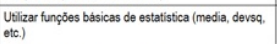 & 2,02 & 16,19 & 35,22 & 46,56 & . & \\
\hline 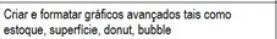 & 4.05 & 17.81 & 40.08 & 38.06 & · & \\
\hline Usar fungheses financeiras & 8.50 & 24.29 & 35.63 & 31,58 & - & - \\
\hline 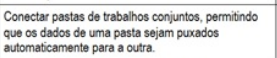 & 12,55 & 25.10 & 32,79 & 29.55 & - & . \\
\hline Exportar dedos para um banco de dados & 13,36 & 28.34 & 30,77 & 27.53 & & \\
\hline Auditoria de Fómula & 20,24 & 23,08 & 30,77 & 25.91 & & \\
\hline Usar funçbes como correspp. e indice & 13,77 & 32,39 & 35,63 & 18.22 & & \\
\hline Atngir Neta & 35,22 & 24,29 & 22,67 & 17,81 & $\cdot$ & \\
\hline Importar dados da Web & 26,72 & 28.34 & 31,17 & 13,77 & & \\
\hline $\begin{array}{l}\text { Importar dados do um banco do dadoses para o Excol } \\
\text { (SOL) }\end{array}$ & 34.82 & 32,39 & 20.24 & 12.55 & & \\
\hline Usar macros do Excel & 15,38 & 36,84 & 36,44 & 11,34 & & \\
\hline Usar o Solver para problemas de programaraşo linear & 40.08 & 27.94 & 21.46 & 10.53 & . & \\
\hline Usar andilise de regressbo & 42,91 & 26.32 & 21,46 & 9,31 & . & \\
\hline Usar o Gerenciador de Cenario & 43,72 & 32,39 & 14.98 & 8.91 & . & \\
\hline Resumir dados com estatisticas descritivas & 42.51 & 27,94 & 21.05 & 8.50 & & \\
\hline Usar Visual Basic (VBA) & 37,25 & 39.68 & 19.03 & 4,05 & & \\
\hline Simulaçoes de Monte Carlo & 54,25 & 25.91 & 17,41 & 2,43 & . & \\
\hline
\end{tabular}

Nota: os asteriscos $\left({ }^{*}\right)$ simbolizam a presença de diferença significativa em relação à variável apresentada. Fonte: dados da pesquisa.

Observa-se que, principalmente, as funções, ferramentas e atividades que envolvem banco de dados, programação e estatísticas são as que apresentam menor nível de conhecimento. Em 11 dos 27 pontos foram encontradas diferenças significativas do nível de conhecimento, a partir do teste de Chi-Quadrado, entre as quatro áreas de atuação avaliadas. Em 10 das 11 diferenças, o menor nível de conhecimento foi dos profissionais ligados à área contábil, e os maiores ficaram principalmente entre os ligados à área de controladoria, seguidos pelos de finanças.

Em termos de posição hierárquica, são encontradas apenas duas diferenças significativas em que o nível hierárquico mais alto apresenta, de maneira geral, maior nível de conhecimento. As diferenças foram observadas principalmente a partir das funções com indicação de nível de conhecimento "bastante experiente" inferior a 50\%. Ao se comparar os resultados da pesquisa de Bradbard et al. (2014) com os presentes resultados, percebe-se que os rankings dos principais conhecimentos são semelhantes, tendo em vista algumas diferenças de classificação, mas nenhuma significativa.

Como nem todas as funções, ferramentas e atividades das planilhas são utilizadas de forma frequente pelos profissionais, solicitou-se que fossem indicadas as 10 mais importantes para sua atividade tomando como base as 27 listadas anteriormente. A tabela 12 indica o ranking das principais indicações, e a existência de diferenças significativas a partir da posição hierárquica e a área de atuação do profissional, diferenças estas que são analisadas posteriormente. Os dados da tabela 12 evidenciam que as principais utilizações pelos profissionais são de ferramentais que permitem tratamento, busca e análise de dados. Ferramentas mais aprofundadas de gestão como solver, análises estatísticas, gerenciamento de cenários e simulações são pouco utilizadas. 
TABELA 12

Ranking das funções, ferramentas e atividade mais utilizadas

\begin{tabular}{|c|c|c|c|}
\hline Funçäo, ferramenta, atividade & $\begin{array}{c}\text { Utilizaçäo } \\
(\%)\end{array}$ & $\begin{array}{l}\text { Área de } \\
\text { atuação }\end{array}$ & Hierarquia \\
\hline Tabelas Dinâmicas & 88,3 & & \\
\hline Usar funçø̄es de procura & 79,4 & . & \\
\hline $\begin{array}{l}\text { Usar as condições em fórmulas com o SE, } \\
\text { CONT.SE e SOMASE }\end{array}$ & 78,9 & & \\
\hline Funçōes Básicas & 78,1 & . & \\
\hline Funçø̃es de filtrar, classificar dados e subtotalizar. & 76,1 & & \\
\hline Funções de formatação & 59,1 & . & \\
\hline $\begin{array}{l}\text { Usar diversos tipos de função para criar fórmulas } \\
\text { complexas }\end{array}$ & 57,9 & & \\
\hline $\begin{array}{l}\text { Usar funç̋̃es do Excel para manipular análise de } \\
\text { textos }\end{array}$ & 46,2 & . & \\
\hline Funçð̃es financeiras & 46,2 & $*$ & \\
\hline Utilizar funçōes básicas de estatistica & 46,2 & & \\
\hline Criar e formatar gráficos avançados & 44,9 & & \\
\hline Usar célula absoluta e relativa de endereçamento & 41,7 & & \\
\hline Formatação condicional & 36,4 & & \\
\hline Macros do Excel & 35,2 & $\cdot$ & \\
\hline Conectar pastas de trabalhos conjuntos & 30,4 & & . \\
\hline Auditoria de fórmulas & 24,7 & & \\
\hline Usar funçōes como CORRESP e ÍNDICE & 18,2 & & \\
\hline Exportar dados para um banco de dados & 17,0 & & \\
\hline Atingir Meta & 15,4 & . & \\
\hline Importar dados de um banco de dados para o Excel & 15,0 & & \\
\hline Usar Visual Basic & 11,3 & & \\
\hline Usar análise de regressão & 10,9 & & \\
\hline Importar dados da Web & 10,5 & & \\
\hline Resumir dados com estatisticas descritivas & 8,9 & & \\
\hline Solver & 8,1 & & \\
\hline Gerenciador de Cenário & 7,7 & & \\
\hline Simulações de Monte Carlo & 7,3 & & \\
\hline
\end{tabular}

Nota: os asteriscos $\left({ }^{*}\right)$ simbolizam a presença de diferença significativa em relação à variável apresentada. Fonte: dados da pesquisa.

Os resultados encontrados por este trabalho diferem em parte dos resultados de Ragland \& Ramachandran (2014). Os profissionais da América Latina entendem as funções mais básicas e de formatação como sendo as menos importantes, enquanto os estadunidenses apontam a elas como as mais importantes, porém esses profissionais apontam as Macros com maior importância.

A tabela 13 apresenta as principais diferenças de utilização entre as áreas de atuação, a partir do teste de Chi-Quadrado. Observa-se de maneira geral que as funções mais simples são indicadas principalmente pelos profissionais que atuam na auditoria e contabilidade, e as mais complexas entre profissionais que indicam ser da área financeira e de controladoria.

TABELA 13

Diferenças significativas em função da área de atuação

\begin{tabular}{|l|c|c|c|c|}
\hline \multicolumn{1}{|c|}{ Função, ferramenta, atividade. } & $\begin{array}{c}\text { Auditoria } \\
\text { (\%) }\end{array}$ & $\begin{array}{c}\text { Contábil } \\
\text { (\%) }\end{array}$ & $\begin{array}{c}\text { Financeira } \\
\text { (\%) }\end{array}$ & $\begin{array}{c}\text { Controladoria } \\
\text { (\%) }\end{array}$ \\
\hline $\begin{array}{l}\text { Usar funçōes de procura (PROCV e } \\
\text { PROCH) }\end{array}$ & 81,9 & 71,1 & 72,7 & 92,6 \\
\hline $\begin{array}{l}\text { Funções básicas (Ex: somar e } \\
\text { subtrair) }\end{array}$ & 82,7 & 81,6 & 65,5 & 77,8 \\
\hline $\begin{array}{l}\text { Funções de formato (Ex: fontes e } \\
\text { formatação numérica) }\end{array}$ & 59,8 & 68,4 & 45,5 & 70,4 \\
\hline $\begin{array}{l}\text { Usar funções do Excel para } \\
\text { manipular análise de textos (EX: } \\
\text { Concatenar, Valor, Num. Caract.) }\end{array}$ & 51,2 & 50,0 & 25,5 & 59,3 \\
\hline $\begin{array}{l}\text { Usar funções financeiras como NPV, } \\
\text { PMT, IRR, PV, FV. }\end{array}$ & 43,3 & 50,0 & 58,2 & 29,6 \\
\hline Usar macros do Excel & 31,5 & 55,3 & 34,5 & 25,9 \\
\hline Atingir meta & 8,7 & 13,2 & 32,7 & 14,8 \\
\hline $\begin{array}{l}\text { Usar funções de procura (PROCV e } \\
\text { PROCH) }\end{array}$ & 81,9 & 71,1 & 72,7 & 92,6 \\
\hline
\end{tabular}

Fonte: dados da pesquisa. 
A tabela 14 demonstra que foi encontrada apenas uma diferença significativa em termos de hierarquia. $\mathrm{O}$ compartilhamento de pastas foi mais indicado conforme o nível hierárquico aumenta.

TABELA 14

Diferenças significativas em função da posição hierárquica

\begin{tabular}{|l|c|c|c|c|}
\hline Função, ferramenta, atividade. & $\begin{array}{c}\text { 0, mesmo } \\
\text { nivel }\end{array}$ & $\begin{array}{c}\text { 1, superior } \\
\text { imediato }\end{array}$ & 2 niveis & $\begin{array}{c}\text { 3 ou } \\
\text { mais }\end{array}$ \\
\hline $\begin{array}{l}\text { Usar o Excel para conectar } \\
\text { pastas de trabalhos conjuntos, } \\
\text { permitindo que os dados de uma } \\
\text { pasta sejam puxados } \\
\text { automaticamente para a outra. }\end{array}$ & $45,5 \%$ & $32,7 \%$ & $17,5 \%$ & $25,9 \%$ \\
\hline
\end{tabular}

Fonte: dados da pesquisa.

Segundo Malik (2005) o volume de informações geradas pelos sistemas de informações das organizações cria grossas camadas que geram sobrecarga de dados que nem sempre são de fácil visibilidade. Em função disso, as organizações têm optado pelo desenvolvimento de DashBoards, que são painéis que traduzem a estratégia da organização em objetivos, métricas, iniciativas e tarefas personalizadas para cada grupo e indivíduo.

Existem softwares específicos para desenvolvimento de DashBoards no mercado. Contudo, as planilhas eletrônicas permitem a construção de DashBoards altamente eficientes, mas para tal é preciso ter conhecimento de funções avançadas bem como de macros, VBA e migração de dados. Dessa forma questionou-se o nível de conhecimento dos profissionais sobre as DashBoards, bem como de seu desenvolvimento.

A tabela 15 demonstra que mais de 46,1\% dos profissionais conhecem e fazem uso de DashBoards, e apenas $12,9 \%$ deles também as desenvolvem. Porém cabe ressaltar que o maior nível de conhecimento e desenvolvimento é presente entre os profissionais que atuam na área financeira e de controladoria.

TABELA 15

Conhecimento e desenvolvimento de DashBoards

\begin{tabular}{|l|c|c|c|c|c|}
\hline \multicolumn{1}{|c|}{$\begin{array}{c}\text { Conhecimento } \\
\text { desenvolvimento }\end{array}$} & $\begin{array}{c}\text { Todos } \\
(\%)\end{array}$ & $\begin{array}{c}\text { Auditoria } \\
(\%)\end{array}$ & $\begin{array}{c}\text { Contábil } \\
(\%)\end{array}$ & $\begin{array}{c}\text { Financeira } \\
(\%)\end{array}$ & $\begin{array}{c}\text { Controladoria } \\
(\%)\end{array}$ \\
\hline $\begin{array}{l}\text { Não sei o que é uma } \\
\text { DashBoard. }\end{array}$ & 53,9 & 63,9 & 75,7 & 27,3 & 33,3 \\
\hline $\begin{array}{l}\text { Utilizo para análises, mas não } \\
\text { desenvolvo. }\end{array}$ & 33,2 & 28,7 & 16,2 & 50,9 & 40,7 \\
\hline $\begin{array}{l}\text { Utilizo para análises e também } \\
\text { as desenvolvo. }\end{array}$ & 12,9 & 7,4 & 8,1 & 21,8 & 25,9 \\
\hline
\end{tabular}

Fonte: dados da pesquisa.

Ao analisar mais profundamente, observa-se que a utilização e desenvolvimento das DashBoards se dá principalmente entre os profissionais da área financeira e de controladoria que desenvolvem orçamento. Esse maior conhecimento é percebido principalmente em profissionais com maior nível hierárquico, em profissionais que atuam na indústria, e de forma menos acentuada em profissionais que atuam em empresas de capital internacional.

Ao analisar o nível de conhecimento e desenvolvimento de DashBoards em função da indicação de conhecimento de Macros, VBA e importação de dados a partir de bancos de dados e da web, fica exposto que ele é bem superior entre os que indicam serem bastante experientes, comparados aos que indicaram nenhum conhecimento. Somente $9 \%$ dos que indicaram ter nenhum conhecimento de VBA desenvolvem Dash, e esta taxa é de $25 \%$ entre os que indicaram serem bastante experientes em VBA. O nível de desconhecimento de DashBoards é de $75 \%$ entre os que não tem conhecimento em macros e é de $40 \%$ entre os que tem nível elevado de macros.

Conforme já exposto, Bradbard et al. (2014) questionaram a percepção que os profissionais tinham sobre o nível de conhecimento dos novos contratados em relação às planilhas eletrônicas. A tabela 16 segue a mesma linha, porém com a inclusão da variável "não sei avaliar". Nela se apresenta, a partir da lista do ranking das principais funções, ferramentas e atividades das planilhas eletrônicas, a percepção do nível de conhecimento 
encontrado entre os novos contratados. Na segunda coluna databela 16 , apresenta-se um ranking a partir do maior para o menor percentual de "Muito conhecimento" indicado. Observa-se que as indicações de maior percentual de "Não sei avaliar" e de "Pouco ou nenhum conhecimento" estão entre as questões que também tem o menor nível de utilização.

TABELA 16

Nível de conhecimento dos novos contratados

\begin{tabular}{|c|c|c|c|c|c|c|}
\hline Uso & $\begin{array}{l}\text { Conhe- } \\
\text { cimento }\end{array}$ & Função, ferramenta, atividade. & $\begin{array}{c}\text { Pouco ou } \\
\text { nentum } \\
\text { conhecimento } \\
(\%)\end{array}$ & $\begin{array}{l}\text { Conhecimento } \\
\text { intermediario } \\
\text { (\%) }\end{array}$ & \begin{tabular}{|c|}
$\begin{array}{c}\text { Muito } \\
\text { conhecimento } \\
\text { (\%) }\end{array}$ \\
\end{tabular} & $\begin{array}{c}\text { Nào sei } \\
\text { avaliar } \\
(\%)\end{array}$ \\
\hline 1 & 6 & Tabelas Dinâmicas & 19,8 & 28,7 & 43,3 & 8,1 \\
\hline 2 & 7 & Usar funçöes de procura & 26,3 & 25,9 & 40,1 & 7,7 \\
\hline 3 & 5 & $\begin{array}{l}\text { Usar as condiçōes em förmulas com o } \\
\text { SE, CONT.SE e SOMASE }\end{array}$ & 19,4 & 30,4 & 44,1 & 6,1 \\
\hline 4 & 1 & Funçōes básicas & 1,6 & 19,8 & 72,1 & 6,5 \\
\hline 5 & 3 & $\begin{array}{l}\text { Funçöes de filtrar, classificar dados e } \\
\text { subtotalizar. }\end{array}$ & 6,9 & 4,0 & 58,3 & 6,5 \\
\hline 6 & 2 & Funções de formataçăo & 4,9 & 27,5 & 60,3 & 7,3 \\
\hline 7 & 8 & $\begin{array}{l}\text { Usar diversos tipos de funçăo para } \\
\text { criar fórmulas complexas }\end{array}$ & 26,3 & 25,9 & 40,1 & 7,7 \\
\hline 8 & 9 & $\begin{array}{l}\text { Usar funçōes do Excel para manipular } \\
\text { analise de textos }\end{array}$ & 23,5 & 34,0 & 35,2 & 7,3 \\
\hline 9 & 15 & Funç̋̄es financeiras & 38,9 & 29,1 & 23,5 & 8,5 \\
\hline 10 & 11 & Utilizar funç̋̃es básicas de estatistica & 27,1 & 33,6 & 30,4 & 8,9 \\
\hline 11 & 12 & Criar e formatar gráficos avançados & 26,3 & 39,7 & 27,5 & 6,5 \\
\hline 12 & 4 & $\begin{array}{l}\text { Usar célula absoluta e relativa de } \\
\text { endereçamento }\end{array}$ & 15,4 & 29,6 & 45,7 & 9,3 \\
\hline 13 & 10 & Formataçãocondicional & 28,3 & 32,0 & 34,0 & 5,7 \\
\hline 14 & 17 & Macros do Excel & 46,2 & 22,3 & 22,3 & 9,3 \\
\hline 15 & 13 & $\begin{array}{l}\text { Conectar pastas de trabalhos } \\
\text { conjuntos }\end{array}$ & 37,7 & 25,9 & 24,3 & 12,1 \\
\hline 16 & 18 & Auditoria de fórmulas & 43,7 & 25,1 & 20,2 & 10,9 \\
\hline 17 & 16 & $\begin{array}{l}\text { Usar funç̧̄es como CORRESPe } \\
\text { INDICE }\end{array}$ & 40,5 & 26,7 & 22,7 & 10,1 \\
\hline 18 & 14 & $\begin{array}{l}\text { Exportar dados para um banco de } \\
\text { dados }\end{array}$ & 42,9 & 21,5 & 23,9 & 11,7 \\
\hline 19 & 20 & Atingir Meta & 46,2 & 24,3 & 18,2 & 11,3 \\
\hline 20 & 21 & $\begin{array}{l}\text { Importar dados de um banco de dados } \\
\text { para o Excel }\end{array}$ & 51,0 & 21,1 & 15,8 & 12,1 \\
\hline 21 & 27 & Usar Visual Basic & 55,1 & 21,9 & 8,9 & 14,2 \\
\hline 22 & 22 & Usar anâlise de regressão & 56,3 & 15,0 & 13,4 & 15,4 \\
\hline 23 & 19 & Importar dados da Web & 45,3 & 22,3 & 20,2 & 12,1 \\
\hline 24 & 23 & $\begin{array}{l}\text { Resumir dados com estatisticas } \\
\text { descritivas }\end{array}$ & 55,1 & 19,0 & 12,6 & 13,4 \\
\hline 25 & 24 & Solver & 55,9 & 17,4 & 12,1 & 14,6 \\
\hline 26 & 25 & Gerenciador de Cenário & 55,9 & 17,8 & 10,9 & 15,4 \\
\hline 27 & 26 & Simulaçōes de Monte Carlo & 59,1 & 14,2 & 9,3 & 17,4 \\
\hline
\end{tabular}

Fonte: dados da pesquisa.

Não são encontradas grandes disparidades entre os grupos de controle estabelecidos.

\section{Considerações finais}

Tendo em vista o cenário que envolve as competências profissionais necessárias ao desenvolvimento das atribuições de maneira eficaz e eficiente em todas as áreas de conhecimento, o presente trabalho teve como objetivo investigar qual é o nível de proficiência dos profissionais da área contábil financeira no uso de planilhas eletrônicas. Nesse sentido, entende-se competência profissional como sendo a capacidade do indivíduo de articular e mobilizar conhecimentos, habilidades e atitudes (De Luiz, 2001).

Dentre os principais resultados do artigo merecem destaque os achados que indicam que a media de autoavaliação dos profissionais, a respeito de seus conhecimentos sobre o uso de planilhas eletrônicas, foi de 7,2 . Essa nota média é ainda menor quando se trata dos conhecimentos dos novos contratados (6,8). Assim, em termos de experiência profissional, quanto mais inexperientes, menor é sua nota de autoavaliação sobre o conhecimento no uso de planilhas eletrônicas. Sendo assim, a academia contábil deve voltar seus olhos para a formação prática e aplicada do estudante, tendo em vista que no inicio de suas carreiras eles tendem a se sentirem inseguros.

Outro importante resultado que não apareceu em estudos anteriores, é o fato de que o conhecimento e utilização das planilhas não é influenciado pelo perfil das empresas, mas sim pelo perfil do profissional. Principalmente em função da área de atuação e posição hierárquica que se encontra. Ressalta-se também que 
não foram observadas diferenças significativas entre os países o que demonstra homogeneidade de percepção por toda América espanhola.

No que tange às origens do conhecimento de planilhas eletrônicas uma boa parte dos profissionais $(51,1 \%)$ afirmou terem adquirido seu conhecimento no próprio trabalho, por meio do uso das ferramentas. Por sua parte, $14,8 \%$ afirmaram ter adquirido essa habilidade na faculdade. Mas esse índice é maior entre os mais novos, o que aponta uma maior utilização desta ferramenta nas universidades. É importante que as universidades busquem continuamente superar a barreira entre academia e mercado. Assim sendo, é necessário que os coordenadores de curso se mantenham atentos às tendências de mercado, de maneira a tornar possível ajustes no projeto político pedagógico do curso.

Em relação ao uso das planilhas eletrônicas os resultados encontrados apontam que as principais utilizações pelos profissionais são de ferramentais que permitem tratamento, busca e análise de dados. Esse resultado diferencia-se dos encontrados por Ragland e Ramachandran (2014), visto que em contexto norte-americano os profissionais fazem uso de funções mais avançadas. As funções mais utilizadas variam de acordo com o nível hierárquico e campo de atuação do profissional.

Em termos de relevância, este artigo está ligado ao fato de que a contabilidade é uma área em constante mudança. Assim, seus profissionais devem estar sempre atualizados, da mesma maneira que as instituições de ensino superior devem gerenciar e atualizar seu currículo para formar profissionais melhor preparados para atender a demanda do mercado de trabalho.

O presente artigo contribui para a prática de coordenadores e professores de cursos da área de negócios ao ressaltar a importância do uso de planilhas eletrônicas e suas principais funções. Estes conteúdos podem ser trabalhados em disciplinas específicas de informática ou dentro de disciplinas que indiquem a necessidade de planilhas, tais como Custos, Orçamento Empresarial e Finanças.

Como possível limitação deste trabalho tem-se o fato de que a lista de funções indicadas nesta pesquisa não representa totalmente todas as funções utilizadas pelos profissionais da área contábil-financeira. Nesse sentido, para pesquisas futuras sugere-se a compreensão do grau em que essas funções disponíveis no Excel podem ser incorporadas nos currículos dos cursos que envolvem a área contábil-financeira. Poder-se-ia de forma complementar, identificar estratégias para melhor preparar os estudantes para possíveis carreiras na área contábil-financeira.

\section{Referências}

Bahador, K., \& Haider, A. (2012). Information technology competencies for Malaysian accountants-an academic's perspective. In ACIS 2012: Proceedings of the 23rd Australasian Conference on Information Systems 2012 (pp. 1-12). ACIS.

Bahador, K., Haider, A., \& Saat, R. (2018). The enhancement of spreadsheet skills among practitioners within small medium accounting firms. International Journal of Engineering \& Technology, 7(4.19), 212-216. Retrieved from https://www.sciencepubco.com/index.php/ijet/article/view/22050

Beuren, I. M. (2006). Como elaborar trabalhos monográficos em contabilidade. São Paulo: Editorial Atlas.

Bradbard, D., Alvis, C., \& Morris, R. (2014). Spreadsheet usage by management accountants: An exploratory study. Journal of Accounting Education, 32(4), 24-30. https://doi.org/10.1016/j.jaccedu.2014.09.001

Burnett, S. (2003). The future of accounting education: A regional perspective. Journal of Education for Business, 78(3), 129-134. https://doi.org/10.1080/08832320309599709

Callegaro, M., Manfreda, K., \& Vehovar, V. (2015). Websurvey Methodology. California: SAGE Publications.

Cardoso, R., Riccio, E., \& Albuquerque, L. (2009). Competências do contador: um estudo sobre a existência de uma estrutura de interdependência. Revista de Administração da USP, 44(4), 365-379. http://rausp.usp.br/wp-cont ent/uploads/files/v4404365.pdf 
Chen, J., Damamtew, D., Banatte, J., \& Mapp, J. (2009). Information technology competencies expected in undergraduate accounting graduates. Research in Higher Education Journal, 3, 1-7. https://www.aabri.com/ma nuscripts/09146.pdf

Cory, S., \& Pruske, K. (2012). Necessary skills for accounting graduates: An exploratory study to determine what the profession wants. ASBBS Proceedings, 19(1), 208-218. http://asbbs.org/files/ASBBS2012V1/PDF/C/CoryS.p $\mathrm{df}$

Costa, R. M. (2012). Os programas de treinamento, desenvolvimento e educação corporativa e o nível de maturidade em gestão de pessoas: Um estudo baseado no People Capability Maturity Model. Dissertação de Mestrado. Pontifícia Universidade Católica do Rio de Janeiro, Rio de Janeiro, RJ, Brasil.

De Luiz, N. (2001). Qualificação, competências e certificação: visão do mundo do trabalho. Formação, Brasília, .(2), 5-15. https://www.paho.org/bra/index.php?option=com_docman\&view=download\&alias $=585$-qualificacaocompetencias-e-certificacao-visao-do-mundo-do-trabalho-5\&category_slug=formacao-e-capacitacao-rh-165\& Itemid $=965$

Depresbiteris, L. (1989). O Desafio da avaliação da aprendizagem: dos fundamentos a uma proposta inovadora. São Paulo, E.P.U.

Dillman, D. (2000). Mail and Internet surveys. New York: John Wiley \& Sons.

Elsaadani, M. (2015). Information and communication technology skills' sufficiency of Egyptian accounting graduates. International Journal of Advanced Information Technology, 5(1/2), 1-11. https://doi.org/10.5121/ijait.2015.5 201

Fleury, M., \& Fleury, A. (2001). Construindo o conceito de competência. Revista de Administração Contemporânea, 5(Edição Especial), 183-196. https://doi.org/10.1590/S1415-65552001000500010

Grimm, S., \& Blazovich, J. (2016). Developing student competencies: An integrated approach to a financial statement analysis project. Journal of Accounting Education, 35, 69-101. https://doi.org/10.1016/j.jaccedu.2016.01.001

Kearns, G. (2014). The importance of Accounting Information System in the Accounting Curricula: A CPA Perspective. AIS Educator Journal, 9(1), 24-40. https://doi.org/10.3194/1935-8156-9.1.24

Lee, C., Tang, H., Sam, K., \& Xiong, G. (2018). Spreadsheet proficiency: Which spreadsheet skills are important? Journal of Information Technology Management, 29(3), 35. http://jitm.ubalt.edu/XXIX-3/article4.pdf

Malik, S. (2005). Enterprise Dashboards: design and best practices. New Jersey: John Wiley \& Sons.

Marin, T., Lima, S., \& Casa Nova, S. (2014). Formação do contador - o que o mercado quer, é o que ele tem? Um estudo sobre o perfil profissional dos alunos de ciências contábeis da FEA-USP. Revista Contabilidade Vista \& Revista, 25(2), 59-83. https://revistas.face.ufmg.br/index.php/contabilidadevistaerevista/article/view/1532

Martins, G., \& Theóphilo, C. (2009). Metodologia da investigação cientifica para ciências sociais aplicadas. São Paulo: Atlas.

Miranda, C. (2011). Ensino em contabilidade gerencial: uma análise comparativa de percepções de importância entre docentes e profissionais, utilizando as dimensões de atividades, artefatos e competências. Tese de Doutorado, Universidade de São Paulo, São Paulo, SP, Brasil.

Osmani, M., Hindi, N., \& Al-Esmail, R. (2017). Examining graduate skills in accounting and finance: The perception of Middle Eastern students. Industry and Higher Education, 31(5), 318-327. https://doi.org/10.1177/095042 2217721759

Pan, P., \& Perera, H. (2012). Market relevance of university accounting programs: Evidence from Australia. Accounting Forum, 36(2), 91-108. https://doi.org/10.1016/j.accfor.2011.11.001

Pathways Commission. (2015). In Pursuit of Accounting's Curricula of the Future. Recuperado de: http:// commons.aahhq.org/groups/2d690969a3/summary;.

Ragland, L., \& Ramachandran, U. (2014). Towards an understanding of excel functional skills needed for a career in public accounting: Perceptions from public accountants and accounting students. Journal of Accounting Education. 32(4), 113-129. https://doi.org/10.1016/j.jaccedu.2014.03.002 
Siegel, G., \& Kulesza, C. (1996). The practice analysis of management accounting. Management Accounting, 70(10), 20-28. https://doi.org/10.12691/jbms-4-1-3

Sithole, S. T. (2015). Quality in accounting graduates: Employer expectations of the graduate skills in the bachelor of accounting degree. European Scientific Journal, 11 (22), 165-180. https://ssrn.com/abstract=3073025

Umbach, P. D. (2004). Web surveys: Best practices. New directions for institutional research, 121, 23-38. https://doi .org/10.1002/ir.98

Waaijer, C., Belder, B., Van, B., Sonneveld, H., \& Van, D. (2015). Survey on the Labour Market Position of PhD graduates. Working in Paper of Centre for Science and Technology Studies. Universidad de Leiden. Leiden: Holanda.

Willis, V. F. (2016). A model for teaching technology: Using Excel in an accounting information systems course.Journal of Accounting Education, 36, 87-99. https://doi.org/10.1016/j.jaccedu.2016.05.002

\section{Notas}

* Artigo de pesquisa científica e tecnológica.

\section{Licencia Creative Commons CC BY 4.0}

Para citar este artigo: Miranda, C. S., Lima, J. P. R., \& Vendramin, E. O. (2020). Domínio das planilhas eletrônicas por profissionais da área contábil-financeira na América hispânica. Cuadernos de Contabilidad, 21. https://doi.org/10.11144/Javeriana.cc21.dpep 